\title{
Maternal gestational diabetes and different indicators of childhood obesity: a large study
}

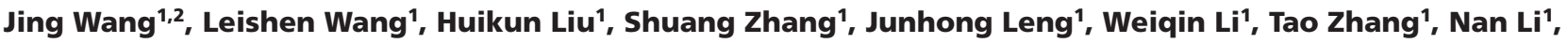 \\ Wei Li ${ }^{1}$, Andrea A Baccarelli ${ }^{3}$, Lifang Hou${ }^{4}$ and Gang $\mathrm{Hu}^{2}$
}

${ }^{1}$ Tianjin Women's and Children's Health Center, Tianjin, China

${ }^{2}$ Chronic Disease Epidemiology Laboratory, Pennington Biomedical Research Center, Baton Rouge, Louisiana, USA

${ }^{3}$ Department of Environmental Health Sciences, Columbia University Mailman School of Public Health, New York, New York, USA

${ }^{4}$ Department of Preventive Medicine, Feinberg School of Medicine, Northwestern University, Chicago, Illinois, USA

Correspondence should be addressed to G Hu: gang.hu@pbrc.edu

\begin{abstract}
Previous studies found conflicting results about the associations between the exposure to hyperglycemia in utero and the later risks of childhood overweight and obesity. The aim of the present study is to compare the children's BMI growth between offspring exposed to maternal gestational diabetes mellitus (GDM) and those not exposed and assess the associations between maternal GDM and their offspring's overweight and obesity risk. We performed a large observational study in 1156 women and their offspring (578 GDM and 578 non-GDM mother-child pairs, matched by their offspring's gender and age). Maternal GDM was diagnosed according to the World Health Organization criteria. Childhood height, weight, waist circumference, body fat and skinfold were measured using standardized methods. After adjustment for maternal and children's characteristics, children born to mothers with GDM during pregnancy had higher mean values of Z scores for BMI-for-age, Z scores for weight-for-age, waist circumferences, body fat, subscapular skinfold and suprailiac skinfold, in comparison with their counterparts born to mothers with normal glucose during pregnancy (all $P$ values $<0.05$ ). Moreover, maternal GDM was associated with a higher risk of childhood overweight and obesity with multivariate-adjusted odds ratios of 1.42 (95\% confidence interval $(\mathrm{Cl}): 1.02-1.97)$ and $1.18(95 \% \mathrm{Cl}: 1.11-1.24)$, respectively, compared with the children of mothers without GDM during pregnancy. This study demonstrates that maternal GDM is an independent risk factor of childhood overweight and obesity and is associated with higher BMI in the offspring.
\end{abstract}

\author{
Key Words \\ - gestational diabetes \\ mellitus \\ - childhood obesity \\ - maternal glucose levels \\ - childhood growth \\ - early childhood risk factors
}

Endocrine Connections (2018) 7, 1464-1471

\section{Introduction}

The worldwide rise in over-nutrition, sedentary life and obesity has resulted in a steep increase in the number of women who develop gestational diabetes mellitus (GDM) during pregnancy (1). Nearly 7\% of pregnancies in the United States were affected by GDM, which is defined as any degree of glucose intolerance with onset or first recognition during pregnancy (2). The global prevalence of GDM ranged from 5.8 to $12.9 \%$ (3). Women with prior
GDM are known to increase the risk of hypertensive disorders of pregnancy, the need for cesarean delivery, the possibility of fetal macrosomia (1) and the long-term risk of developing type 2 diabetes in later life, compared with non-GDM women (4).

With respect to the long-term effects on the growth and development of children with GDM mothers, there are conflicting findings in previous studies. In the
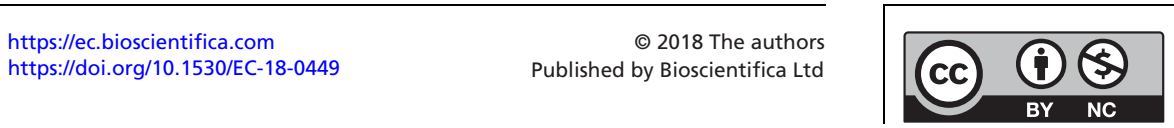

This work is licensed under a Creative Commons Attribution-NonCommercial 4.0 International License. 
Northwestern Diabetes in Pregnancy Study in Chicago, diabetes during pregnancy (GDM and preexistent diabetes) was positively associated with the offspring's BMI at birth and after 5 years old $(5,6)$. The offspring of Pima Indian women with preexistent diabetes and GDM had much higher rates of obesity at age 5-19 years, compared with their counterparts born to prediabetic and nondiabetic women $(7,8)$. However, these differences may be due to the high type 2 diabetes (T2D) risk in the specialized population from the Pima Indians and a specialized pregnancy clinical population in Chicago (9). Regarding to the general population, two recent studies from the Hyperglycemia and Adverse Pregnancy Outcome study (HAPO) (10) and Kaiser Permanente Northwest and Hawaii (11) presented that maternal hyperglycemia during pregnancy increased the offspring's risk of overweight and obesity among 7-year-old girls and during the first decade among normal birth weight infants, respectively. However, other studies did not find a clear association between maternal GDM and obesity in offspring of more than 5 years old $(12,13,14)$. Thus, more studies are expected to provide evidence and illustrate the impact of GDM on children's growth and development. The present study aims to compare different indicators of childhood obesity between offspring exposed to maternal GDM and those not exposed and assess the associations between maternal GDM and their offspring's overweight and obesity risk.

\section{Methods}

\section{GDM screening process}

We used a two-step approach in the GDM diagnosis in Tianjin, China. We first invited all pregnant women (at their 26-30 gestational weeks) to participate in a 1-h oral glucose tolerance test (OGTT) with $50 \mathrm{~g}$ glucose load in their community health centers. Then, those whose glucose reading $\geq 7.8 \mathrm{mmol} / \mathrm{L}$ were referred to the Tianjin Women's and Children's Health Center to undergo a 2-h OGTT with $75 \mathrm{~g}$ glucose load. If the pregnant women met the 1999 World Health Organization (WHO)'s criteria of diabetes (fasting glucose $\geq 7 \mathrm{mmol} / \mathrm{L}$ or 2 -h glucose $\geq 11.1 \mathrm{mmol} / \mathrm{L}$ ) or impaired glucose tolerance (IGT) (2-h glucose $\geq 7.8 \mathrm{mmol} / \mathrm{L}$ and $<11.1 \mathrm{mmol} / \mathrm{L}$ ), they would be diagnosed as GDM (15). From 1999, all pregnant women living in the six urban districts of Tianjin have been screened for GDM (16).

$$
\begin{aligned}
& \text { https://ec.bioscientifica.com } \\
& \text { https://doi.org/10.1530/EC-18-0449 }
\end{aligned}
$$

() 2018 The authors Published by Bioscientifica Ltd

\section{Study population}

We conducted a large study in 578 GDM mother-child pairs and their 578 counterparts with non-GDM mothers, matched by children's genders and ages. The GDM mothers came from the Tianjin Gestational Diabetes Mellitus Prevention Program (17), a randomized controlled trial conducted among GDM women living in the six urban districts in Tianjin. A total of 4644 eligible women, who were diagnosed with GDM between 2005 and 2009, were invited to join the program by mailing. During August 2009 to July 2011, a total of 1263 GDM women at their postpartum 1-5 years finished the baseline survey. Of them, 83 were diagnosed as having type 2 diabetes, and the rest 1180 GDM women then attended the Tianjin Gestational Diabetes Mellitus Prevention Program. The recruitment, inclusion and exclusion criteria have been described in detail elsewhere (17). We randomly chose 578 GDM mother-child pairs who finished the year 1 or 2 follow-up survey and also stored blood samples. Simultaneously, we also enrolled 578 non-GDM mother-child pairs, with age and sex frequency matched to the 578 children of GDM mothers (Fig. 1). We collected written informed consents from all

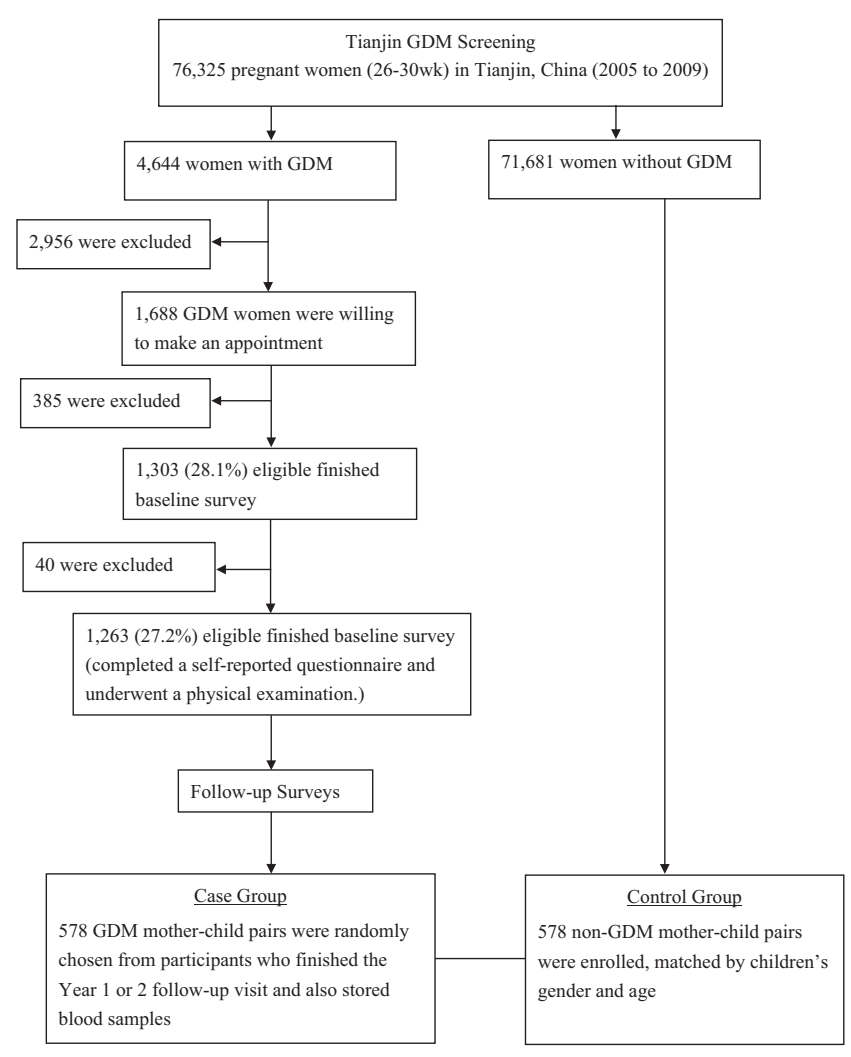

Figure 1

Flow chart.

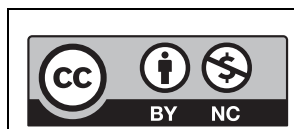

This work is licensed under a Creative Commons Attribution-NonCommercial 4.0 International License. 
participants, and this study was approved by the Human Subjects Committee of Tianjin Women's and Children's Health Center.

Mothers' information was collected by a selfadministered questionnaire, including socio-demographic characteristics, such as age, marital status, education $(<13$, $13-16$, and $\geq 16$ years), family income $(<5000,5000-8000$ and $\geq 8000$ yuan/month), and occupation; pregnancy outcomes (prepregnancy weight, weight gain during pregnancy, gestational age and the number of births in the index pregnancy) and lifestyle in the past year, such as smoking status (non-smokers, former smokers and current smokers), passive smoking, drinking status, sitting time and leisure-time physical activity $(0,1-29$, and $\geq 30 \mathrm{~min} /$ day). Children's information was collected by another questionnaire completed by their mothers, including children's general information, such as gender, birth date, age, birth weight, birth length, the mode of infant feeding within the first 6 months (exclusive formula, mixed breast and formula or exclusive breast) and lactation duration; history of diseases and medication; dietary habits (using a validated food frequency questionnaire (FFQ) (18)) and routine activities (indoor and outdoor activities, screening watching time and sleep duration).

All mother-child pairs underwent a physical examination. Using the standardized protocol, all participants' height and weight were measured in light indoor clothing and without shoes by trained research doctors. Moreover, the children's physical examination also included the measurement of body fat, waist circumference, triceps skinfold, subscapular skinfold and suprailiac skinfold. Body weight was measured with a beam balance scale to the nearest $0.1 \mathrm{~kg}$; height was measured by a stadiometer to the nearest $0.1 \mathrm{~cm}$. Waist circumference was measured midway between the 10th rib and the top of the iliac crest to the nearest $0.1 \mathrm{~cm}$. Body fat was measured by a body composition analyzer (InBody J20) to the nearest $0.1 \%$. Triceps skinfold, subscapular skinfold and suprailiac skinfold were measured by skinfold caliper to the nearest $0.5 \mathrm{~cm}$.

\section{Calculation of BMI}

BMI was obtained by dividing weight in kilograms by the square of height in meters. All mothers' prepregnancy BMI calculation used their self-reported prepregnancy weight and their height. According to the Chinese BMI cut-offs (19), prepregnancy BMI was categorized as $<24$, $24-27.9$ and $\geq 28 \mathrm{~kg} / \mathrm{m}^{2}$. Children's BMI calculation used their body weight and height examined in the study visit.

https://ec.bioscientifica.com

https://doi.org/10.1530/EC-18-0449 (c) 2018 The authors Published by Bioscientifica Ltd

\section{Children's Z scores and overweight/obesity}

Children's Z scores (including Z scores for height-forage (Z-height), Z scores for weight-for-age (Z-weight), $Z$ scores for BMI-for-age (Z-BMI)), calculated based on the protocol from the WHO, are gender-independent classification systems, representing equivalent height/ weight/BMI-for-age percentile based on the WHO growth reference (20).

Children's overweight and obesity was defined by children's Z-BMI: we defined normal weight as a BMI less than the 85th percentiles for age and gender based on the WHO growth reference (Z-score <1.035), overweight as a BMI above the 85th percentiles (Z-score $\geq 1.035$ ), and obesity as a BMI above the 90th percentiles (Z-score $\geq 1.645$ ) (21). Central obesity was defined as waist circumference $\geq$ the 90 th percentiles for age- and genderspecific distribution, according to the National Health and Nutrition Examination Survey (NHANES) III (22). High body fat was defined as body fat $\geq$ the 90 th percentiles of the NHANES IV (23) (since the references were available from 5 years old, we defined high body fat only among the children over 5 years old).

\section{Statistical analyses}

We used $t$-test and chi-square test to compare the general characteristics (continuous and categorical variables) of both mothers and children according to maternal GDM status. General linear models were applied to assess the differences in children's Z-BMI, Z-weight, Z-height, body fat, waist circumference, triceps skinfold, subscapular skinfold and suprailiac skinfold according to maternal GDM status. Cox proportional hazards models were used to estimate hazards ratios for children's overweight, obesity, central obesity and high body fat according to maternal GDM status. The analyses included three multivariable adjusted models: Model 1 adjusted for maternal age, gestational age and education; Model 2 adjusted for the variables in Model 1 and also for maternal smoking status, passive smoking status, alcohol drinking status, as well as children's feeding method during the first 6 months after birth, children's vegetables and fruits intake frequency, outdoor time, screen watching time and sleeping duration; Model 3 adjusted for the variables in Model 2 and also for maternal prepregnancy BMI and maternal gestational weight gain. All analyses were performed using IBM SPSS Statistics 24.0 (IBM SPSS) with a statistical significance at 0.05 .

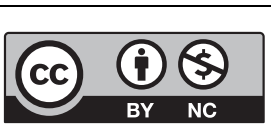

This work is licensed under a Creative Commons Attribution-NonCommercial 4.0 International License. 
Table 1 Maternal and children's characteristics according to maternal gestational diabetes status.

\begin{tabular}{|c|c|c|c|}
\hline \multirow[b]{2}{*}{ Maternal and children's characteristics } & \multirow[b]{2}{*}{ Non-GDM } & \multirow[b]{2}{*}{ GDM } & \multirow[b]{2}{*}{$P$ value } \\
\hline & & & \\
\hline Number of subjects & 578 & 578 & \\
\hline \multicolumn{4}{|l|}{ Maternal characteristics } \\
\hline Age at delivery, years & $29.7 \pm 2.91$ & $30.5 \pm 3.58$ & $<0.001$ \\
\hline Gestational age at delivery, weeks & $39.1 \pm 1.52$ & $39.1 \pm 1.34$ & 0.54 \\
\hline Prepregnancy BMI, kg/m² & $21.4 \pm 2.94$ & $22.9 \pm 3.06$ & $<0.001$ \\
\hline Prepregnancy BMI categories, \% & & & $<0.001$ \\
\hline$<24.0$ & 85.6 & 68.0 & \\
\hline $24.0-27.9$ & 10.7 & 25.8 & \\
\hline$\geq 28$ & 3.6 & 6.2 & \\
\hline Gestational weight gain, kg & $18.2 \pm 6.70$ & $16.6 \pm 5.85$ & $<0.001$ \\
\hline Education, \% & & & $<0.001$ \\
\hline$\leq 12$ years & 10.7 & 20.1 & \\
\hline $13-15$ years & 75.6 & 72.8 & \\
\hline$\geq 16$ years & 13.7 & 7.1 & \\
\hline Current smokers, \% & 3.8 & 1.7 & 0.046 \\
\hline Alcohol drinkers, \% & 31.7 & 21.6 & $<0.001$ \\
\hline \multicolumn{4}{|l|}{ Child characteristics } \\
\hline Boy, \% & 52.2 & 52.2 & 1.00 \\
\hline Age, months & $70.4 \pm 14.7$ & $70.4 \pm 14.9$ & 0.98 \\
\hline Mode of infant feeding, $\%$ & & & 0.45 \\
\hline Exclusive breastfeeding & 40.9 & 44.3 & \\
\hline Mixed breast and formula & 44.5 & 42.9 & \\
\hline Exclusive formula feeding & 14.6 & 12.8 & \\
\hline Vegetables intake frequency, \% & & & $<0.001$ \\
\hline$\leq 1$ time/day & 13.1 & 3.3 & \\
\hline 2 times/day & 81.3 & 93.6 & \\
\hline$\geq 3$ times/day & 5.5 & 3.1 & \\
\hline Fruits intake frequency, $\%$ & & & 0.60 \\
\hline$<1$ time/day & 3.1 & 4.2 & \\
\hline 1 time/day & 38.4 & 37.0 & \\
\hline Screen watching time, h/day & $0.95 \pm 0.76$ & $1.17 \pm 0.83$ & $<0.001$ \\
\hline Sleeping duration, \% & & & 0.019 \\
\hline$\leq 8 \mathrm{~h} /$ day & 11.1 & 14.5 & \\
\hline 9-10h/day & 67.3 & 69.6 & \\
\hline$\geq 11 \mathrm{~h} /$ day & 21.6 & 15.9 & \\
\hline Birth BMI, kg/m² & 13.3 & 13.7 & $<0.001$ \\
\hline Height, cm & $118 \pm 9.18$ & $118 \pm 9.75$ & 0.50 \\
\hline Z-score for height-for-age & $0.69 \pm 1.01$ & $0.75 \pm 1.01$ & 0.25 \\
\hline Weight, kg & $22.1 \pm 5.99$ & $23.1 \pm 6.91$ & 0.011 \\
\hline Z-score for weight-for-age & $0.45 \pm 1.20$ & $0.70 \pm 1.26$ & 0.001 \\
\hline Body mass index, $\mathrm{kg} / \mathrm{m}^{2}$ & $15.7 \pm 2.30$ & $16.2 \pm 2.59$ & $<0.001$ \\
\hline Z-score for body mass index-for-age & $0.02 \pm 1.28$ & $0.34 \pm 1.35$ & $<0.001$ \\
\hline Waist circumference, $\mathrm{cm}$ & $54.7 \pm 6.09$ & $56.3 \pm 6.77$ & $<0.001$ \\
\hline Body fat, $\%$ & $19.1 \pm 7.42$ & $20.7 \pm 7.97$ & $<0.001$ \\
\hline Triceps skinfold, mm & $12.8 \pm 5.36$ & $12.7 \pm 5.81$ & 0.69 \\
\hline Subscapular skinfold, mm & $7.22 \pm 3.82$ & $8.10 \pm 4.42$ & $<0.001$ \\
\hline Suprailiac skinfold, mm & $9.67 \pm 5.96$ & $11.6 \pm 6.99$ & $<0.001$ \\
\hline Overweight (Z-BMI $\geq 1.035), \%$ & 18.5 & 27.0 & 0.001 \\
\hline Obesity (Z-BMI $\geq 1.645), \%$ & 10.6 & 17.0 & 0.002 \\
\hline Central obesity, $\%$ & 5.7 & 8.8 & 0.04 \\
\hline High body fat, \% & 19.9 & 28.6 & 0.001 \\
\hline
\end{tabular}

Values are means \pm s.D. unless otherwise specified.

GDM, gestational diabetes mellitus.

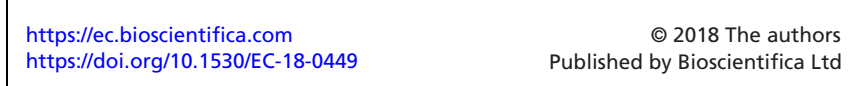




\section{Results}

Table 1 presents maternal and children's characteristics according to maternal GDM status. Compared with nonGDM mothers, GDM mothers were older at delivery, more overweight and obese before pregnancy, less current smokers and less alcohol drinkers and had less gestational weight gain and less education level. Compared with children born to non-GDM mothers, children born to GDM mothers had higher birth BMI, longer screen watching time but shorter sleeping duration.

After adjustment for maternal age, gestational age, education, current smoking status, passive smoking status, alcohol drinking status and children's feeding method, children's vegetables and fruits intake frequency, outdoor time, screen watching time and sleeping duration (multivariable-adjusted Model 2), children born to GDM mothers had higher mean values of Z-BMI (0.33 vs 0.03$)$, Z-weight (0.70 vs 0.45$)$, body fat (20.7 vs $19.1 \%)$, waist circumference ( 56.3 vs $54.7 \mathrm{~cm})$, subscapular skinfold $(8.08$ vs $7.24 \mathrm{~mm}$ ) and suprailiac skinfold (11.6 vs $9.68 \mathrm{~mm}$ ) than children born to non-GDM mothers (Table 2).
After additional adjustment for maternal prepregnancy BMI and gestational weight gain (multivariable-adjusted Model 3), these differences still remained significant.

The multivariable-adjusted (Model 2) odds ratios among children of GDM mothers compared with children of non-GDM mothers were 1.55 (95\% confidence interval (CI) 1.14-2.10) for overweight, 1.65 (95\% CI 1.14-2.40) for obesity and 1.53 (95\% 1.11-2.12) for high body fat, respectively (Table 3). When further adjusting for maternal prepregnancy BMI and gestational weight gain, these associations were somewhat attenuated but remained significant. There was no significant association between GDM status and children's central obesity.

\section{Discussion}

In this large study, we found that children born to GDM mothers had higher Z-weight, Z-BMI, waist circumference, body fat, subscapular skinfold and suprailiac skinfold and were associated with increased risks of overweight, obesity and high body fat compared with children born to

Table 2 Comparison of children's measurements according to maternal gestational diabetes status.

\begin{tabular}{|c|c|c|}
\hline Children's measurements & Multivariable-adjusted models & Non-GDM $(n=578)$ \\
\hline \multirow[t]{3}{*}{ Z-score of BMI-for-age } & Model 1 & $0.02(0.06)$ \\
\hline & Model 2 & $0.03(0.06)$ \\
\hline & Model 3 & $0.07(0.05)$ \\
\hline \multirow[t]{3}{*}{ Z-score of weight-for-age } & Model 1 & $0.45(0.05)$ \\
\hline & Model 2 & $0.45(0.05)$ \\
\hline & Model 3 & $0.48(0.05)$ \\
\hline \multirow[t]{3}{*}{ Z-score of height-for-age } & Model 1 & $0.68(0.04)$ \\
\hline & Model 2 & $0.68(0.04)$ \\
\hline & Model 3 & $0.68(0.04)$ \\
\hline \multirow[t]{3}{*}{ Body fat, $\%$} & Model 1 & $19.1(0.32)$ \\
\hline & Model 2 & $19.1(0.32)$ \\
\hline & Model 3 & $19.3(0.32)$ \\
\hline \multirow[t]{3}{*}{ Waist circumference, cm } & Model 1 & $54.7(0.24)$ \\
\hline & Model 2 & $54.7(0.25)$ \\
\hline & Model 3 & $54.9(0.24)$ \\
\hline \multirow[t]{3}{*}{ Triceps skinfold, mm } & Model 1 & $12.9(0.22)$ \\
\hline & Model 2 & $12.8(0.22)$ \\
\hline & Model 3 & $12.9(0.22)$ \\
\hline \multirow[t]{3}{*}{ Subscapular skinfold, mm } & Model 1 & $7.26(0.17)$ \\
\hline & Model 2 & $7.24(0.17)$ \\
\hline & Model 3 & $7.34(0.17)$ \\
\hline \multirow[t]{3}{*}{ Suprailiac skinfold, mm } & Model 1 & $9.70(0.26)$ \\
\hline & Model 2 & $9.68(0.26)$ \\
\hline & Model 3 & $9.87(0.26)$ \\
\hline
\end{tabular}

\begin{tabular}{c}
\hline GDM $(n=578)$ \\
\hline $0.33(0.06)$ \\
$0.33(0.06)$ \\
$0.29(0.05)$ \\
$0.70(0.05)$ \\
$0.70(0.05)$ \\
$0.67(0.05)$ \\
$0.76(0.04)$ \\
$0.76(0.04)$ \\
$0.76(0.04)$ \\
$20.7(0.32)$ \\
$20.7(0.32)$ \\
$20.5(0.32)$ \\
$56.3(0.24)$ \\
$56.3(0.25)$ \\
$56.1(0.24)$ \\
$12.7(0.22)$ \\
$12.7(0.22)$ \\
$12.6(0.22)$ \\
$8.07(0.17)$ \\
$8.08(0.17)$ \\
$7.99(0.17)$ \\
$11.6(0.26)$ \\
$11.6(0.26)$ \\
$11.4(0.26)$ \\
\end{tabular}

\begin{tabular}{c}
\hline P value \\
\hline$<0.001$ \\
$<0.001$ \\
0.006 \\
0.001 \\
0.001 \\
0.009 \\
0.18 \\
0.21 \\
0.17 \\
0.001 \\
$<0.001$ \\
0.008 \\
$<0.001$ \\
$<0.001$ \\
$<0.001$ \\
0.59 \\
0.70 \\
0.29 \\
0.001 \\
0.001 \\
0.007 \\
$<0.001$ \\
$<0.001$ \\
$<0.001$ \\
\hline
\end{tabular}

Data are means (s.E.). Model 1 adjusted for maternal age, gestational age, education, and children's age; for Z-score of BMI-for-age, Z-score of weightfor-age and Z-score of height-for-age, adjusted for maternal age, gestational age and education only. Model 2 adjusted for covariates in Model 1 and also for maternal smoking status, passive smoking status, alcohol drinking status, as well as children's feeding status, vegetables and fruits intake frequency, outdoor time, screening watching time and sleeping duration. Model 3 adjusted for in Model 2 and also for maternal prepregnancy BMI and weight gain during pregnancy.

BMI, body mass index; GDM, gestational diabetes mellitus.

$$
\begin{aligned}
& \text { https://ec.bioscientifica.com } \\
& \text { https://doi.org/10.1530/EC-18-0449 } 2018 \text { The authors } \\
& \text { Published by Bioscientifica Ltd }
\end{aligned}
$$


Table 3 Odds ratios for childhood overweight, obesity, central obesity and high body fat by maternal GDM status.

\begin{tabular}{|c|c|c|}
\hline Outcomes & & No. of cases/participants \\
\hline \multirow[t]{2}{*}{ Overweight } & Non-GDM & $107 / 578$ \\
\hline & GDM & $156 / 578$ \\
\hline \multirow[t]{2}{*}{ Obesity } & Non-GDM & $61 / 578$ \\
\hline & GDM & $98 / 578$ \\
\hline \multirow[t]{2}{*}{ Central obesity } & Non-GDM & $33 / 578$ \\
\hline & GDM & $51 / 578$ \\
\hline \multirow[t]{2}{*}{ High body fat } & Non-GDM & $96 / 483$ \\
\hline & GDM & $140 / 489$ \\
\hline
\end{tabular}

\begin{tabular}{|c|c|c|}
\hline \multicolumn{3}{|c|}{ Odds ratios $(95 \% \mathrm{Cls})$} \\
\hline Model 1 & Model 2 & Model 3 \\
\hline 1.00 & 1.00 & 1.00 \\
\hline $1.60(1.20-2.13)$ & $1.55(1.14-2.10)$ & $1.42(1.02-1.97)$ \\
\hline 1.00 & 1.00 & 1.00 \\
\hline $1.73(1.22-2.46)$ & $1.65(1.14-2.40)$ & $1.18(1.11-1.24)$ \\
\hline 1.00 & 1.00 & 1.00 \\
\hline $1.60(1.00-2.55)$ & $1.60(0.97-2.62)$ & $1.60(0.94-2.70)$ \\
\hline 1.00 & 1.00 & 1.00 \\
\hline $1.60(1.18-2.17)$ & $1.53(1.11-2.12)$ & $1.47(1.03-2.08)$ \\
\hline
\end{tabular}

Model 1 adjusted for maternal age, gestational age, and education. Model 2 adjusted for covariates in Model 1 and also for maternal smoking status, passive smoking status, alcohol drinking status, as well as children's feeding method, vegetables and fruits intake frequency, outdoor time, screening watching time and sleeping duration. Model 3 adjusted for in Model 2 and also for maternal prepregnancy BMI and weight gain during pregnancy. $\mathrm{Cl}$, confidence intervals; GDM, gestational diabetes mellitus.

non-GDM mothers. These associations were independent of maternal prepregnancy BMI, gestational weight gain and other related maternal and infant factors.

As known in the previous studies, in utero exposure to GDM is a risk factor of macrosomia and large for gestational age at birth and developing obesity and type 2 diabetes during adolescence or young adulthood in the offspring (24). However, debates on the associations between maternal GDM status and childhood overweight and obesity risks have never stopped. Studies of Northwestern Diabetes in Pregnancy Study in Chicago $(5,6)$, Pima Indian (8), HAPO in Hongkong (10) and Kaiser Permanente centers (11) claimed to find a positive association between maternal GDM and childhood obesity, while other studies including one HAPO study in UK argued that little association existed $(12,13,14$, $25,26)$. Discrepancies in these findings may be due to small sample sizes of GDM-exposed children or research conducted among high type 2 diabetes (T2D) risk populations (Pima Indians and Chicago study (9)). The present study included a large sample size of GDM and non-GDM mother-child pairs and had enough power to compare the differences of offspring's growth between GDM and non-GDM exposure. Also, we controlled various covariates in the multivariable-adjusted analysis, such as maternal social-economic characteristics, lifestyle factors, infant feeding status, children's diet and lifestyle, maternal weight gain during pregnancy and prepregnancy BMI, which were identified as important confounders of this association (27).

Evidence from human and animal research indicates that the environment in utero plays an important role on the growth of infants. The possible explanation underlying the findings could be 'metabolic imprinting', which is known as the process by which a stimulus or insult occurring during a critical period of development has a long-term effect on the physiologic and metabolic responses of the offspring' (28). It represented a determinant of an over-nutritional status of fetus and further leading to offspring's diseases later in life (29). One of the underlying mechanisms may be the delivery of excessive nutrients from mothers to the fetus; maternal glucose but not insulin can cross the placenta which in turn influences the development of the fetus in utero and even long-term health (30). Previous animal models provided strong evidence that maternal diabetes increased the risks of offspring's obesity and diabetes: GDM affected offspring's obesity and insulin resistance in the livers, and further was associated with susceptibility to type 2 diabetes mellitus $(31,32)$. Increasing obesity among children was also associated with lifestyle changes, such as over-nutrition and more sedentary time. In this study, we also found that children born to GDM mothers had longer screen watching time but shorter sleeping duration than their counterparts. In the analysis, we controlled these diet and lifestyle variables, but they may affect children's overweight and obesity in the real world.

We tried to assess children's obesity in a more detailed way than previous studies, so we included not only BMI, weight, height, overweight and obesity, but also body fat, waist circumference, triceps skinfold, subscapular skinfold and suprailiac skinfold as evaluating indicator of obesity. Moreover, the data were based on the Asian population, who are of increasing burden of childhood obesity and diabetes; as such identification and understanding of early life risk factors are particularly relevant. Finally, maternal GDM was diagnosed based on the WHO criteria. There were several limitations in our study. One limitation of the study was that it was a cross-sectional study. Thus, we could not make cause-and-effect inferences. Second, maternal 
prepregnancy weight and gestational weight gain were based on self-reported data, which may introduce recall bias. Nevertheless, validation studies in the United States and England have found good concordance between self-reported information during pregnancy and clinical records (33). Moreover, the children's body measurements taken at different ages may conceal at what age this association between GDM and childhood overweight/ obesity becomes apparent.

In conclusion, maternal GDM is an independent risk factor of childhood overweight and obesity, and it is associated with children's faster growth of BMI. Children who are exposed to hyperglycemia in utero have higher risks of becoming overweight and obese. Therefore, for this high-risk population, appropriate intervention strategies are needed.

\section{Declaration of interest}

The authors declare that there is no conflict of interest that could be perceived as prejudicing the impartiality of the research reported.

\section{Funding}

This study was supported by the Tianjin Women's and Children's Health Center, Tianjin Public Health Bureau, European Foundation for the Study of Diabetes (EFSD)/Chinese Diabetes Society (CDS)/Lilly programme for Collaborative Research between China and Europe. Dr Hu was partly supported by the grant from the National Institute of Diabetes and Digestive and Kidney Diseases (R01DK100790) and the National Institute of General Medical Sciences (U54GM104940) of the National Institutes of Health.

\section{Author contribution statement}

G H and J W designed this study. L W, H L, J L, S Z and W L conducted the field research. J W, W L, T Z and N L conducted data organization and analysis. J W drafted the manuscript. A A B, L H and G H critically reviewed and revised the manuscript.

\section{Acknowledgements}

The authors would like to appreciate all the hard-working people from Tianjin Women's and Children's Health Center dedicating to the Tianjin Gestational Diabetes Mellitus Prevention Program.

\section{References}

1 American Diabetes Association. Gestational diabetes mellitus. Diabetes Care 200326 (Supplement 1) S103-S105.

2 Metzger BE \& Coustan DR. Summary and recommendations of the Fourth International Workshop-Conference on Gestational Diabetes Mellitus. The Organizing Committee. Diabetes Care 199821 (Supplement 2) B161-B167.

3 Zhu Y \& Zhang C. Prevalence of gestational diabetes and risk of progression to type 2 diabetes: a global perspective. Current Diabetes Reports 201616 7. (https://doi.org/10.1007/s11892-015-0699-x)

4 Bellamy L, Casas JP, Hingorani AD \& Williams D. Type 2 diabetes mellitus after gestational diabetes: a systematic review and meta-analysis. Lancet 2009373 1773-1779. (https://doi.org/10.1016/ S0140-6736(09)60731-5)

5 Silverman BL, Rizzo T, Green OC, Cho NH, Winter RJ, Ogata ES, Richards GE \& Metzger BE. Long-term prospective evaluation of offspring of diabetic mothers. Diabetes 199140 (Supplement 2) 121-125. (https://doi.org/10.2337/diab.40.2.S121)

6 Silverman BL, Rizzo TA, Cho NH \& Metzger BE. Long-term effects of the intrauterine environment. The Northwestern University diabetes in pregnancy center. Diabetes Care 199821 (Supplement 2) B142-B149.

7 Pettitt DJ, Baird HR, Aleck KA, Bennett PH \& Knowler WC. Excessive obesity in offspring of Pima Indian women with diabetes during pregnancy. New England Journal of Medicine 1983308 242-245. (https://doi.org/10.1056/NEJM198302033080502)

8 Pettitt DJ, Nelson RG, Saad MF, Bennett PH \& Knowler WC. Diabetes and obesity in the offspring of Pima Indian women with diabetes during pregnancy. Diabetes Care 199316 310-314. (https://doi. org/10.2337/diacare.16.1.310)

9 Dabelea D. The predisposition to obesity and diabetes in offspring of diabetic mothers. Diabetes Care 200730 (Supplement 2) S169-S174. (https://doi.org/10.2337/dc07-s211)

10 Tam WH, Ma RCW, Ozaki R, Li AM, Chan MHM, Yuen LY, Lao TTH, Yang X, Ho CS, Tutino GE, et al. In utero exposure to maternal hyperglycemia increases childhood cardiometabolic risk in offspring. Diabetes Care 201740 679-686. (https://doi. org/10.2337/dc16-2397)

11 Hillier TA, Pedula KL, Vesco KK, Oshiro CE \& Ogasawara KK. Impact of maternal glucose and gestational weight gain on child obesity over the first decade of life in normal birth weight infants. Maternal and Child Health Journal 201620 1559-1568. (https://doi.org/10.1007/ s10995-016-1955-7)

12 Whitaker RC, Pepe MS, Seidel KD, Wright JA \& Knopp RH. Gestational diabetes and the risk of offspring obesity. Pediatrics 1998 101 E9. (https://doi.org/10.1542/peds.101.2.e9)

13 Gillman MW, Rifas-Shiman S, Berkey CS, Field AE \& Colditz GA. Maternal gestational diabetes, birth weight, and adolescent obesity. Pediatrics 2003111 e221-e226. (https://doi.org/10.1542/ peds.111.3.e221)

14 Tam WH, Ma RC, Yang X, Ko GT, Tong PC, Cockram CS, Sahota DS, Rogers MS \& Chan JC. Glucose intolerance and cardiometabolic risk in children exposed to maternal gestational diabetes mellitus in utero. Pediatrics 2008122 1229-1234. (https://doi.org/10.1542/ peds.2008-0158)

15 WHO Consultation. Definition, Diagnosis and Classification of Diabetes Mellitus and Its Complications. Part 1: Diagnosis and Classification of Diabetes Mellitus. Geneva, Switzerland: World Health Organization, 1999.

16 Li W, Liu H, Qiao Y, Lv F, Zhang S, Wang L, Leng J, Qi L, Tuomilehto J \& Hu G. Metabolic syndrome of weight change from pre-pregnancy to 1-5 years post-partum among Chinese women with prior gestational diabetes. Diabetic Medicine 201532 1492-1499. (https://doi.org/10.1111/dme.12790)

17 Hu G, Tian H, Zhang F, Liu H, Zhang C, Zhang S, Wang L, Liu G, Yu Z, Yang X, et al. Tianjin Gestational Diabetes Mellitus Prevention Program: study design, methods, and 1-year interim report on the feasibility of lifestyle intervention program. Diabetes Research and Clinical Practice 201298 508-517. (https://doi.org/10.1016/j. diabres.2012.09.015)

18 Li YP, He YN, Zhai FY, Yang XG, Hu XQ, Zhao WH \& Ma GS. [Comparison of assessment of food intakes by using 3 dietary survey methods]. Zhonghua Yu Fang Yi Xue Za Zhi 200640 273-280.

19 Zhou B. [Predictive values of body mass index and waist circumference to risk factors of related diseases in Chinese adult population]. Zhonghua Liu Xing Bing Xue Za Zhi 200223 5-10.

20 World Health Organization. The WHO Child Growth Standards. Geneva, Switzerland: World Health Organization, 2006.
This work is licensed under a Creative Commons Attribution-NonCommercial 4.0 International License. 
21 Ogden CL, Carroll MD, Kit BK \& Flegal KM. Prevalence of obesity and trends in body mass index among US children and adolescents, 1999-2010. JAMA 2012307 483-490. (https://doi.org/10.1001/ jama.2012.40)

22 Fernandez JR, Redden DT, Pietrobelli A \& Allison DB. Waist circumference percentiles in nationally representative samples of African-American, European-American, and Mexican-American children and adolescents. Journal of Pediatrics 2004145 439-444. (https://doi.org/10.1016/j.jpeds.2004.06.044)

23 Laurson KR, Eisenmann JC \& Welk GJ. Body fat percentile curves for U.S. children and adolescents. American Journal of Preventive Medicine 201141 S87-S92. (https://doi.org/10.1016/j.amepre.2011.06.044)

24 Reece EA. The fetal and maternal consequences of gestational diabetes mellitus. Journal of Maternal-Fetal and Neonatal Medicine 2010 23 199-203. (https://doi.org/10.3109/14767050903550659)

25 Thaware PK, McKenna S, Patterson CC, Hadden DR, Pettitt DJ \& McCance DR. Untreated mild hyperglycemia during pregnancy and anthropometric measures of obesity in offspring at Age 5-7 years. Diabetes Care 201538 1701-1706. (https://doi.org/10.2337/ dc14-2797)

26 Pettitt DJ, McKenna S, McLaughlin C, Patterson CC, Hadden DR $\&$ McCance DR. Maternal glucose at 28 weeks of gestation is not associated with obesity in 2-year-old offspring: the Belfast Hyperglycemia and Adverse Pregnancy Outcome (HAPO) family study. Diabetes Care 201033 1219-1223. (https://doi.org/10.2337/ dc09-2384)
27 Lawlor DA. The Society for Social Medicine John Pemberton Lecture 2011. Developmental overnutrition-an old hypothesis with new importance? International Journal of Epidemiology 201342 7-29. (https://doi.org/10.1093/ije/dys209)

28 Sullivan EL \& Grove KL. Metabolic imprinting in obesity. Forum of Nutrition 201063 186-194.

29 Waterland RA \& Garza C. Potential mechanisms of metabolic imprinting that lead to chronic disease. American Journal of Clinical Nutrition 199969 179-197. (https://doi.org/10.1093/ajcn/69.2.179)

30 Fraser A \& Lawlor DA. Long-term health outcomes in offspring born to women with diabetes in pregnancy. Current Diabetes Reports 2014 14 489. (https://doi.org/10.1007/s11892-014-0489-x)

31 Oh W, Gelardi NL \& Cha CJ. Maternal hyperglycemia in pregnant rats: its effect on growth and carbohydrate metabolism in the offspring. Metabolism 198837 1146-1151. (https://doi. org/10.1016/0026-0495(88)90192-8)

32 Yamashita H, Shao J, Qiao L, Pagliassotti M \& Friedman JE. Effect of spontaneous gestational diabetes on fetal and postnatal hepatic insulin resistance in Lepr(db/+) mice. Pediatric Research $2003 \mathbf{5 3}$ 411-418. (https://doi.org/10.1203/01.PDR.0000049667.58071.7D)

33 Dietz P, Bombard J, Mulready-Ward C, Gauthier J, Sackoff J, Brozicevic P, Gambatese M, Nyland-Funke M, England L, Harrison L, et al. Validation of self-reported maternal and infant health indicators in the Pregnancy Risk Assessment Monitoring System. Maternal and Child Health Journal 201418 2489-2498. (https://doi. org/10.1007/s10995-014-1487-y)

Received in final form 14 November 2018

Accepted 30 November 2018

Accepted Preprint published online 3 December 2018 https://ec.bioscientifica.com https://doi.org/10.1530/EC-18-0449 (c) 2018 The authors Published by Bioscientifica Ltd

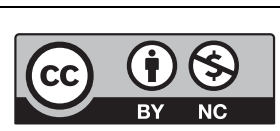

This work is licensed under a Creative Commons Attribution-NonCommercial 4.0 International License. 